\title{
Comparison of urinary thallium levels in non-occupationally exposed people and workers
}

\author{
James F. Staff • Richard J. Cotton • \\ Nicholas D. Warren · Jackie Morton
}

Received: 12 June 2012/ Accepted: 7 February 2013/Published online: 28 February 2013

(C) Crown Copyright 2013

\begin{abstract}
Purpose To determine a reference background urinary thallium level; to compare urinary thallium data from workers to this background level; to investigate factors affecting these levels and whether creatinine correction is appropriate.

Methods Urine samples from non-occupationally exposed people ( $n=273$, from 113 individuals) and workers ( $n=896$, from 447 individuals) were analysed for thallium by ICP-MS. A reference background level was calculated, defined as the 95th percentile value of a nonoccupationally exposed population. Worker data were divided into two subsets: thallium workers (those who work directly with thallium or its compounds) and general workers; and compared to the background level. Bayesian linear mixed effects modelling was used to investigate factors affecting urinary thallium concentration and the efficacy of creatinine correction for the determination of urinary thallium.

Results The reference background urinary thallium level is $0.27 \mu \mathrm{mol} / \mathrm{mol}$ creatinine (creatinine-corrected) or $0.40 \mu \mathrm{g} / \mathrm{l}$ (uncorrected). Median values were $0.11 \mu \mathrm{mol} / \mathrm{mol}$ creatinine or $0.17 \mu \mathrm{g} / \mathrm{l}$ for non-occupationally exposed people, $0.12 \mu \mathrm{mol} / \mathrm{mol}$ creatinine or $0.20 \mu \mathrm{g} / \mathrm{l}$ for general workers and $0.19 \mu \mathrm{mol} / \mathrm{mol}$ creatinine or $0.41 \mu \mathrm{g} / \mathrm{l}$ for thallium workers. Variation was lower in creatinine-corrected models. Nine per cent of samples from general workers and $39 \%$ of samples from thallium workers exceeded the creatinine-corrected background level. By
\end{abstract}

J. F. Staff $(\bowtie)$ - R. J. Cotton · N. D. Warren · J. Morton

Health and Safety Laboratory, Harpur Hill, Buxton,

Derbyshire SK17 9JN, UK

e-mail: james.staff@hsl.gsi.gov.uk
2010, $90 \%$ of all workers had urinary thallium levels below the 95th percentile reference background level.

Conclusions Urinary thallium concentrations were higher in thallium workers than non-occupationally exposed people and general workers. Creatinine correction is appropriate.

Keywords Thallium · Urine - Occupational exposure · Biological monitoring · Creatinine correction - ICP-MS

\section{Introduction}

Once known as "the poisoners' poison" due to its severe toxicity and lack of a distinctive taste or smell, thallium can still present a risk to workers today. Thallium and its compounds are not classified as human carcinogens. However, they are extremely toxic and so are nevertheless potentially very harmful (Kazantzis 2007). They have a UK workplace exposure limit (WEL) of $0.1 \mathrm{mg} / \mathrm{m}^{3}$, a NIOSH Recommended Exposure Limit (REL) of $0.1 \mathrm{mg} / \mathrm{m}^{3}$, a US OSHA Permissable Exposure Limit (PEL) of $0.1 \mathrm{mg} / \mathrm{m}^{3}$ (Institut für Arbeitsschutz der Deutschen Gesetzlichen Unfallversicherung 2012), an ACGIH Threshold Limit Value (TLV) of $0.1 \mathrm{mg} / \mathrm{m}^{3}$ (ACGIH 2012) and also a NIOSH Skin (SK) notation, indicating significant potential for absorption through the skin, leading to systemic toxicity (Health and Safety Executive 2007). However, no maximum workplace concentration (MAK) or biological exposure value (BAT)values for thallium and its compounds have yet been published.

Much of the existing knowledge of the toxic effects of thallium is derived from studies of individual incidents of acute thallium exposure (Zhao et al. 2008; Tsai et al. 2006; Pelclová et al. 2009). Amongst papers published on the subject of thallium exposure, few have investigated the 
possibility and/or effects of low-level occupational exposure. The German Federal Environment Agency has defined a human biomonitoring (HBM-I) value of $5 \mu \mathrm{g} / \mathrm{l}$ for urinary thallium in adults, below which no adverse health effects are expected (Umweltbundesamt 2011). Few previous studies have been carried out to determine background levels of thallium in the non-occupationally exposed population (Caldwell et al. 2005; White and Sabbioni 1998; Heitland and Köster 2006; Hoet et al. 2013). Of these, only the publication by White and Sabbioni studied a UK population, and this considered only nonoccupationally exposed individuals, with no investigation of worker exposure.

The two main industrial applications of thallium are in optical products and electronics. These applications are very specialised, and there are few industrial sites in the UK using thallium or its compounds. However, the relatively small number of workers involved in these industries could potentially be at risk from occupational exposure to thallium. A noninvasive approach to assess exposure to thallium, based on analysis of thallium in urine, would aid exposure assessment. Several publications have used urinary thallium as the exposure marker (Marcus 1985; Tsai et al. 2006; Zhao et al. 2008).

Non-occupational exposure to thallium occurs from a variety of sources, including food, air, drinking water and soil. It has been speculated that cigarette smoke may also be a source of thallium. However, food is the major route of exposure. (Canadian Council of Ministers of the Environment 1999). A study by Sherlock and Smart in 1986 estimated the average UK dietary intake of thallium to be about $0.005 \mathrm{mg} /$ day. The most likely route is through the consumption of fruit and vegetables that take up thallium from the soil, in particular brassicae (Sherlock and Smart 1986).

This study determines a reference background urinary thallium level, defined here as the 95th percentile value in a non-occupationally exposed population (Umweltbundesamt 2011). The study also analyses existing thallium worker data and compares it to this background level. In addition, the study uses statistical modelling to look at whether or not factors such as age, gender, smoking or the time of day of sample micturition significantly affect the urinary thallium concentration and also to investigate the merit of using creatinine correction for the measurement of urinary thallium.

\section{Methods}

This study analyses two datasets of urinary thallium measurements: A volunteer study conducted in 2010 on nonoccupationally exposed people, and a set of occupational biological monitoring data from samples sent to the UK's Health and Safety Laboratory (HSL) between 1996 and 2010. Descriptive statistics of the sample cohort are provided in Table 1.

Sample collection from non-occupationally exposed individuals

Anonymous urine samples ( $n=273$, from 113 individuals) were collected from staff at the Health and Safety Laboratory (Buxton, Derbyshire, UK) and their friends/relatives. All participating volunteers provided informed consent, in accordance with HSG 167 (Health and Safety Executive 1997). Participants provided their initials, date of birth, information on male/female, smoker/non-smoker, date of sample collection and time of sample collection. Samples were collected in $30 \mathrm{ml}$ polystyrene urine collection bottles (Sterilin Ltd., Newport, UK), and upon arrival were frozen at $<20^{\circ} \mathrm{C}$ until analysis for creatinine and thallium.

\section{Collection of worker data}

Over the period February 1996-December 2010, 896 urine samples from 447 individuals (of whom 172 gave repeat samples) were sent by occupational health professionals to aid the assessment of worker exposure to thallium and other metals. This dataset was divided into two subsets. The first subset, designated as "thallium workers", came from workers involved in industries with a known risk of direct exposure to thallium or its compounds, such as the manufacture of optical technology and electronics. Samples from these workers were analysed specifically for thallium. The second subset, designated as "general workers", came from workers in industries with no specific risk of thallium exposure, such as foundries, metal recycling and environmental management. Samples from these workers were analysed for thallium as part of a multi-element suite of analyses. Thallium is only used in very specialised applications, and in very low quantities, so we would not expect occupational exposure of workers within this subset. However, we do not have enough information about these workers or their working conditions to conclude that no occupational exposure will occur.

Analytical procedures

\section{Urinary thallium}

Urine samples were analysed by inductively coupled plasma mass spectrometry (ICP-MS). Over the 15-year period, ICP-MS instruments used for the analysis of urinary thallium were updated. In 2010, the samples from non-occupationally exposed people were analysed using an 
Table 1 Descriptive statistics of the sample cohort

\begin{tabular}{|c|c|c|c|c|c|c|c|c|c|}
\hline & \multicolumn{3}{|c|}{ Non-occupationally exposed } & \multicolumn{3}{|c|}{ General worker } & \multicolumn{3}{|c|}{ Thallium worker } \\
\hline & $\mathrm{All}^{\dagger}$ & Male & Female & $\mathrm{All}^{\dagger}$ & Male & Female & $\mathrm{All}^{\dagger}$ & Male & Female \\
\hline Number of samples & 273 & 179 & 94 & 565 & 472 & 85 & 331 & 300 & 24 \\
\hline Number of smokers & 20 & 8 & 12 & 208 & 187 & 21 & 75 & 64 & 11 \\
\hline Number of non-smokers & 253 & 171 & 82 & 231 & 187 & 44 & 89 & 83 & 6 \\
\hline Mean age (years) & 41.2 & 42.5 & 38.5 & 37.1 & 38.4 & 30.0 & 41.5 & 41.5 & 41.9 \\
\hline \multicolumn{10}{|l|}{ Number of individuals contributing } \\
\hline 1 sample & 41 & 28 & 13 & 238 & 202 & 34 & 37 & 23 & 9 \\
\hline 2 & 43 & 26 & 17 & 70 & 53 & 14 & 18 & 13 & 4 \\
\hline 3 & 3 & 2 & 1 & 38 & 34 & 4 & 8 & 7 & 1 \\
\hline 4 & 4 & 1 & 3 & 9 & 9 & 0 & 4 & 3 & 1 \\
\hline$\geq 5$ & 22 & 16 & 6 & 6 & 5 & 1 & 19 & 19 & 0 \\
\hline Total number of individuals & 113 & 73 & 40 & 361 & 303 & 53 & 86 & 65 & 15 \\
\hline Number of non-detects & 0 & 0 & 0 & 67 & 48 & 17 & 11 & 8 & 3 \\
\hline Number of samples with creatinine $<3$ or $>30 \mathrm{mmol} / 1$ & 44 & 12 & 32 & 53 & 37 & 15 & 8 & 6 & 2 \\
\hline
\end{tabular}

${ }^{\dagger}$ Including samples for which there was no declaration of gender

X7 Series 2 ICP-MS (Thermo-Fisher Scientific, Hemel Hempstead, UK), and the samples from workers over the 15-year period had almost all been analysed using an Elan 6100 ICP-MS (PerkinElmer, Beaconsfield, UK).

The instrument conditions for the X7 Series 2 ICP-MS (Thermo-Fisher Scientific, Hemel Hempstead, UK) used direct nebulisation in normal mode with optimised conditions. Extraction voltage was typically $-100 \mathrm{~V}$, Rf Power $1,400 \mathrm{~W}$, focus voltage $12.0 \mathrm{~V}$ and nebuliser gas flow rate (using a Burgener Miramist nebuliser) $0.83 \mathrm{l} / \mathrm{min}$. The instrument was tuned on a daily basis to ensure optimisation. Dwell times were $50 \mathrm{~ms}$ for ${ }^{205} \mathrm{Tl}$ and $10 \mathrm{~ms}$ for ${ }^{195} \mathrm{Pt}$. Fifty sweeps were carried out per replicate and 3 replicates per sample.

The instrument conditions for the Elan 6100 ICP-MS (PerkinElmer, Beaconsfield, UK) also used direct nebulisation in normal mode with optimised conditions. The instrument was tuned daily to ensure optimisation. A Ryton Scott cross-flow nebuliser was used. Typical instrument conditions used were a nebuliser gas flow rate of $1 \mathrm{l} / \mathrm{min}$, Rf Power $1,400 \mathrm{~W}$ and lens voltage $9 \mathrm{~V}$. Dwell times were $100 \mathrm{~ms}$ for ${ }^{205} \mathrm{Tl}$ and $50 \mathrm{~ms}$ for ${ }^{195} \mathrm{Pt}$. Fifty sweeps were carried out per replicate and 3 replicates per sample.

Multi-element standard solutions were prepared from a $100 \mathrm{mg} / \mathrm{L}$ Primar multi-element standard solution (BDH, Poole, UK) in $1 \%$ v/v nitric acid (Romil Ltd, Cambridge, UK). The final calibration range was $0.1-25 \mu \mathrm{g} / \mathrm{l}$ for the $\mathrm{X} 7$ Series 2 ICP-MS and 2-20 $\mu \mathrm{g} / \mathrm{l}$ for the Elan $6100 \mathrm{ICP}-\mathrm{MS}$.

Urine samples were defrosted at room temperature and mixed on sample rollers for a minimum of $20 \mathrm{~min}$. All urine samples and quality control (QC) samples were diluted 1 in 20 for the non-occupationally exposed study (analysed by X7 Series 2 ICP-MS) and 1 in 5 for the worker sample analysis (analysed by Elan 6100 ICP-MS) with solutions containing nitric acid $(1 \% \mathrm{v} / \mathrm{v}$ for $\mathrm{X} 7$ Series 2, $2 \% \mathrm{v} / \mathrm{v}$ for Elan 6100) (Fisher Scientific, Loughborough, UK), $0.1 \% \mathrm{~m} / \mathrm{v}$ EDTA $(0.05 \% \mathrm{~m} / \mathrm{v}$ for $\mathrm{X} 7$ Series 2, $0.1 \% \mathrm{~m} / \mathrm{v}$ for Elan 6100) (Fisher Scientific, Loughborough, UK) and $10 \mu \mathrm{g} / \mathrm{l}$ platinum as the internal standard (BDH, Poole, UK). The newer instrument is more sensitive, allowing us to run samples with a greater degree of dilution, and thereby avoid detrimental effects to the instrument caused by running samples with a more concentrated matrix.

External QC samples were Lyphochek Urine Metals Control levels 1 and 2 (Bio-Rad Laboratories Ltd, Hemel Hempstead, UK) and were analysed at the start, end and after every 20 samples (Level 1 Lot 69131: certified range 6.8-10.3 $\mu \mathrm{g} / \mathrm{l}$, Level 2 Lot 69122: certified range 136-203 $\mu \mathrm{g} / \mathrm{l})$. All QC results fell within the certified range. QC values obtained for Level 1 Lot 69131 were as follows: X7 Series $2-n=126$, mean $8.5 \mu \mathrm{g} / \mathrm{l}$, standard deviation (SD) $0.801 \mu \mathrm{g} / \mathrm{l}$; Elan $6100-n=80$, mean $8.5 \mu \mathrm{g} / \mathrm{l}$, SD $0.463 \mu \mathrm{g} / \mathrm{l}$. QC values obtained for Level 2 Lot 69122 were as follows: X7 Series $2-n=112$, mean $169 \mu \mathrm{g} / \mathrm{l}, \quad$ SD $5.52 \mu \mathrm{g} / \mathrm{l}$; Elan $6100-n=149$, mean $169 \mu \mathrm{g} / \mathrm{l}, \mathrm{SD} 8.29 \mu \mathrm{g} / \mathrm{l}$.

\section{Urinary creatinine}

Creatinine was determined by an automated alkaline picrate method (Cocker et al. 2011), using a COBAS FARA spectrophotometer (Roche Diagnostic Systems, Basel, Switzerland), a COBAS MIRA spectrophotometer (Roche Diagnostic Systems, Basel, Switzerland) or an ABX Pentra 
400 spectrophotometer (HORIBA ABX UK, Northampton, UK).

An internal QC material made from a pooled urine sample and stored frozen in $1 \mathrm{ml}$ aliquots was used. The QC sample was thawed at room temperature before use and analysed after each calibration (acceptable range 5.29-6.13 mmol/l). All QC results fell within the acceptable range.

\section{Method validation}

The data analysed were obtained using two different ICPMS instruments. The worker thallium data were determined using the older PerkinElmer Elan 6100 ICP-MS (PerkinElmer, Beaconsfield, UK), whereas the samples from non-occupationally exposed people were analysed using the newer X7 Series 2 (Thermo-Fisher Scientific, Hemel Hempstead, UK). Comparison of the two ICP-MS instruments demonstrated that they produced results that were consistent with one another. Samples including Bio-Rad Lyphochek Urine Metals Controls, TEQAS quarterly and G-EQAS external quality assurance (EQA) samples were analysed on the X7 Series 2 ICP-MS and compared with the data obtained by previous analysis on the Elan 6100 instrument-a good correlation $\left(R^{2}=0.9852\right)$ was obtained.

During the analysis of the samples from non-occupationally exposed people, the limit of detection (LOD) for the study was $2.97 \mathrm{ng} / \mathrm{l}$, based on the mean of the blank samples from all runs, plus three times the standard deviation of this mean (McNaught and Wilkinson 1997). All results were greater than the LOD, and so no non-detects were observed in this dataset.

For the worker thallium data, analysed using the PerkinElmer Elan 6100 instrument, any results falling below $0.5 \mathrm{nmol} / \mathrm{l}(0.1 \mu \mathrm{g} / \mathrm{l})$ were classified as non-detects. This constituted $9 \%$ of the results. Note that the Bayesian mixed effects models (see below) inherently account for non-detects and so special treatment was not required.

\section{Statistical analyses}

Statistical calculations were performed using R 2.14.1 (R Development Core Team 2010) and WinBUGS (Lunn et al. 2000). Statistics calculated included arithmetic standard deviations and empirical percentiles. Since the worker data contained non-detects (left censored values), the means and standard deviations were estimated using maximum likelihood estimation, assuming a lognormal distribution (Helsel 2010).

Three Bayesian mixed effects models were fitted. The first was fitted to the log-transformed (non-creatinine-corrected) volunteer measurements to determine whether smoking, gender, age and time of day had an effect. The value of the exponent to which the creatinine concentration (by which the uncorrected values would then be divided) would be raised to give the best fit to the data was also calculated. If this is closer to one than to zero, this would suggest that creatinine correction is beneficial.

The first Bayesian model had the following structure:

$$
\begin{aligned}
\ln \left(\text { thallium }_{i, j}\right)= & \mu+\beta_{1} \ln \left(\text { creatinine }_{i, j}\right)+\beta_{2} I\left(\text { smoking }_{j}\right) \\
& +\beta_{3} \text { gender }_{j}+\beta_{4} \text { age }_{i, j}+\beta_{5}\left(\text { timeofday }_{i, j}\right. \\
& +\delta_{j}+\varepsilon_{i, j}
\end{aligned}
$$

where $f(x)=\sin \left(\frac{\pi}{12} x-8\right)$.

The subscript ${ }_{\mathrm{i}, \mathrm{j}}$ refers to the $i$ th measurement on the $j$ th individual. The variables in the above equation are as follows: thallium, the urinary concentration in $\mu \mathrm{g} / \mathrm{l} ; \mu$, the mean (log-scale) non-smoking male value (the intercept); creatinine is the creatinine concentration in $\mathrm{mmol} / \mathrm{l}$ corresponding to that measurement; I(smoking), an indicator variable denoting that the measurement was taken on a smoker; gender, the gender of the person for that measurement; age, the age of the person for that measurement, in years; and timeofday, the time of day that the micturition occurred, as the number of hours after midnight. Exploratory data analysis revealed that the thallium concentrations appeared to vary cyclically, with a peak close to 14:00. This motivated the use of the sine function for the timeofday term. The fixed effects corresponding to these variables are $\beta_{1}, \beta_{2}, \beta_{3}$ and $\beta_{4}$, and $\delta_{j}$ is the random effect of the $j$ th individual. The $\delta_{j}$ values are assumed to be normally distributed with mean zero, and standard deviation $\sigma_{\text {between-person. }} \varepsilon_{i, j}$ is the residual variation of the $i$ th urinary measurement on the $j$ th worker. These values are assumed to be normally distributed with mean zero and standard deviation $\sigma_{\text {within-person }}$.

A second model was also fitted to the non-occupationally exposed data, this time to the creatinine-corrected thallium concentrations. Apart from no longer having creatinine as a fixed effect, the model is otherwise identical to the first.

The third Bayesian mixed effects model was fitted to the full dataset. In this third model, age and time of day were not included, since those values were not available for the worker data. An additional factor for working group (nonoccupationally exposed, general worker, thallium worker) was included, and each of these groups had separate between- and within-person variance components.

Note that sample date was not included as a fixed effect, since the range of sample dates, particularly for thallium workers, was too short to meaningfully infer any time trend.

All Bayesian models were fitted using Markov chain Monte Carlo methods (MCMC) implemented in WinBUGS (Lunn et al. 2000) using five chains, run for one hundred 
thousand iterations each, after the first thousand ("burnin") values were discarded. Non-informative priors were used and convergence was determined by visual inspection of the chains. Variables were considered to be nonsignificant if their $95 \%$ credible interval (the Bayesian equivalent of a confidence interval) for $\beta$ included zero. These nonsignificant terms were sequentially removed from the model.

\section{Results}

Summary statistics

Descriptive statistics of the sample cohort are provided in Table 1. The non-occupationally exposed group generated 273 urine samples (all with detectable thallium levels), collected from 113 non-occupationally exposed people, of which 72 gave multiple samples. The age range of participants was 7-66 years. There were 896 samples from workers, comprising 565 general worker samples (12\% nondetects) from 361 people, of which 123 provided repeat samples, and 331 samples ( $3 \%$ nondetects) from 86 thallium workers, of which 49 provided repeat samples. The age range of workers sampled was $16-75$ years. No people provided samples in multiple working categories, and thus, the combined datasets consisted of 1169 samples $(7 \%$ nondetects) from 560 people, of which 244 provided repeat samples.

Summary statistics from the analysis of the samples are presented in Table 2. An examination of empirical percentiles of the distributions of the three working groups shows non-occupationally exposed people and general workers at similar levels, with urinary thallium concentrations from thallium workers at higher levels. The median, creatinine-corrected, urinary thallium concentration was $0.11 \mu \mathrm{mol} / \mathrm{mol}$ creatinine for non-occupationally exposed people, $0.12 \mu \mathrm{mol} / \mathrm{mol}$ creatinine for general workers and $0.19 \mu \mathrm{mol} / \mathrm{mol}$ creatinine for thallium workers. The equivalent 95th percentiles were $0.27,0.35$ and $4.30 \mu \mathrm{mol} / \mathrm{mol}$ creatinine, respectively. This pattern was also seen in the uncorrected values, with medians of $0.17,0.20$ and $0.41 \mu \mathrm{g} / \mathrm{l}$, respectively, and 95 th percentiles of $0.40,0.61$ and $10.02 \mu \mathrm{g} / \mathrm{l}$, respectively.

Those 95 th percentiles for non-occupationally exposed people $(0.27 \mu \mathrm{mol} / \mathrm{mol}$ creatinine and $0.40 \mu \mathrm{g} / \mathrm{l}$, from 273 samples) correspond to the "background level". Noting that creatinine correction can introduce differences between genders in measured thallium levels (illustrated by the difference between parts a) and b) in Fig. 2), genderspecific creatinine-corrected 95th percentile background levels of $0.20 \mu \mathrm{mol} / \mathrm{mol}$ creatinine for males $(n=179)$ and $0.35 \mu \mathrm{mol} / \mathrm{mol}$ creatinine for females $(n=94)$ are also defined.

Of the worker samples analysed in this study, $39 \%$ of thallium worker samples and only $9 \%$ of general worker samples had a urinary thallium concentration that exceeded the creatinine-corrected 95th percentile background level.

Variation differed between the three groups; the standard deviations were $0.07 \mu \mathrm{mol} / \mathrm{mol}$ creatinine for nonoccupationally exposed people, $0.15 \mu \mathrm{mol} / \mathrm{mol}$ creatinine for general workers and $1.96 \mu \mathrm{mol} / \mathrm{mol}$ creatinine for thallium workers.

Boxplots given in Fig. 1 illustrate these findings. Samples from general workers exhibit slightly more variation than from non-occupationally exposed people but have similar medians; samples from thallium workers display both higher levels and more variation than either of the other two working groups. Men accounted for the majority of the elevated thallium levels, though this is likely to be a consequence of $91 \%$ of the thallium worker samples coming from men. Differences between measurements in smokers and non-smokers were not significant.

The possibility of a time trend for workers over the sampling period was also considered. However, $86 \%$ of the thallium worker samples were taken during the years 2006-2010, so only this relatively short period could sensibly be taken into account. Figure 3 illustrates the worker

Table 2 Summary statistics for uncorrected and creatinine-corrected urinary thallium levels

\begin{tabular}{|c|c|c|c|c|c|c|c|c|c|}
\hline & \multicolumn{3}{|c|}{ Non-occupationally exposed } & \multicolumn{3}{|c|}{ General worker } & \multicolumn{3}{|c|}{ Thallium worker } \\
\hline & $\mathrm{All}^{\dagger}$ & Male & Female & $\mathrm{All}^{\dagger}$ & Male & Female & $\mathrm{All}^{\dagger}$ & Male & Female \\
\hline \multicolumn{10}{|l|}{ Uncorrected data } \\
\hline Median $(\mu \mathrm{g} / \mathrm{l})$ & 0.17 & 0.19 & 0.13 & 0.20 & 0.20 & 0.20 & 0.41 & 0.41 & 0.41 \\
\hline 95th percentile $(\mu \mathrm{g} / \mathrm{l})$ & 0.40 & 0.41 & 0.36 & 0.61 & 0.61 & 0.41 & 10.02 & 10.23 & 0.99 \\
\hline Standard deviation $(\mu \mathrm{g} / \mathrm{l})$ & 0.15 & 0.14 & 0.13 & 0.16 & 0.17 & 0.11 & 2.51 & 2.67 & 0.37 \\
\hline \multicolumn{10}{|l|}{ Creatinine-corrected data } \\
\hline Median $(\mu \mathrm{mol} / \mathrm{mol})$ & 0.11 & 0.11 & 0.14 & 0.12 & 0.12 & 0.14 & 0.19 & 0.19 & 0.16 \\
\hline 95th percentile $(\mu \mathrm{mol} / \mathrm{mol})$ & 0.27 & 0.20 & 0.35 & 0.35 & 0.29 & 0.45 & 4.30 & 4.39 & 0.48 \\
\hline Standard deviation $(\mu \mathrm{mol} / \mathrm{mol})$ & 0.07 & 0.05 & 0.09 & 0.15 & 0.13 & 0.21 & 1.96 & 2.05 & 0.16 \\
\hline
\end{tabular}


Fig. 1 Boxplots of creatininecorrected urinary thallium levels across the whole dataset, and split by working group, gender and smoking status. The boxes represent the 25th, 50th and 75th percentiles, whilst the bars extend to the 10th and 90th percentiles. Values falling outside these ranges are represented by individual points. The number of observations represented by each plot is displayed at the top

Table 3 Urinary thallium predictions from Bayesian linear mixed effects modelling on the unexposed group

a) Model-predicted values are for uncorrected thallium concentrations (nmol/l) divided by (creatinine concentrations ( $\mu \mathrm{mol} / \mathrm{l})$ raised to the creatinine correction exponent). b) Modelpredicted values are for creatinine-corrected thallium concentrations $(\mu \mathrm{mol} / \mathrm{mol})$. Models are fitted to the logtransformed data
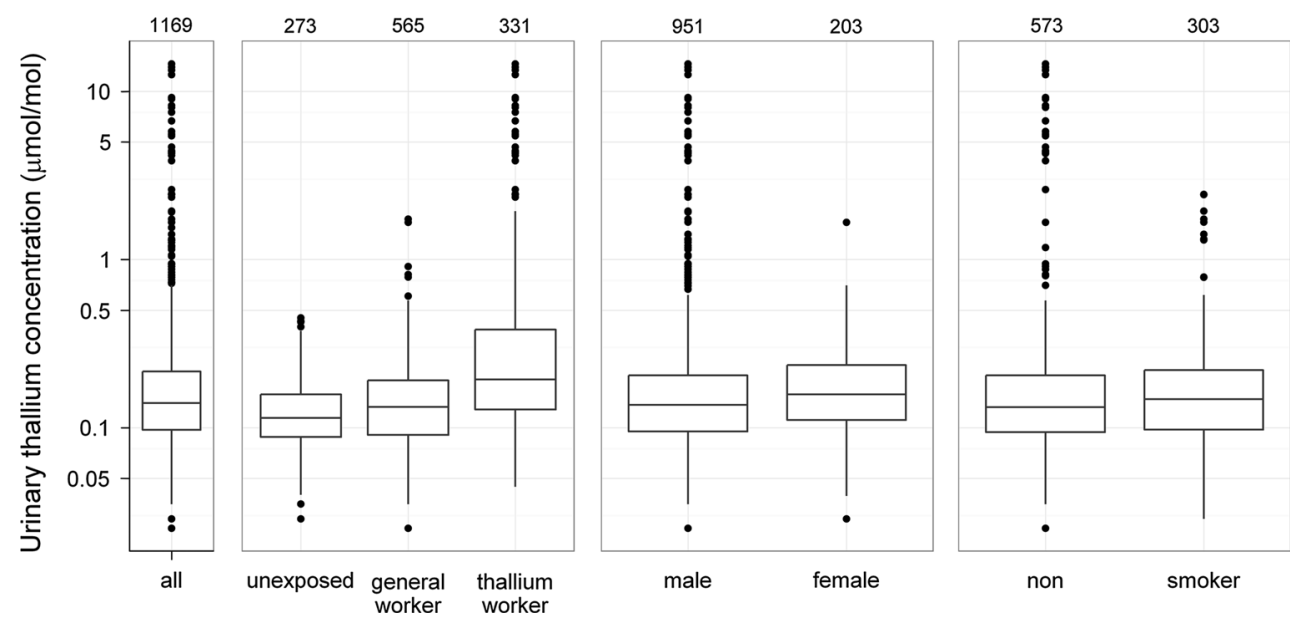

Estimate (95\% confidence interval)

a)

Creatinine correction exponent

Model-predicted value, 8 am or 8 pm

Daily \% increase (2 pm versus $2 \mathrm{am}$ )

$\sigma_{\text {between-person }}$

$\sigma_{\text {within-person }}$

b)

Model-predicted value, women, 8 am or $8 \mathrm{pm}(\mu \mathrm{mol} / \mathrm{mol})$

Model-predicted value, men, 8 am or $8 \mathrm{pm}(\mu \mathrm{mol} / \mathrm{mol})$

Daily \% increase (2 pm versus $2 \mathrm{am})$

$\sigma_{\text {between-person }}$

$\sigma_{\text {within-person }}$
$0.77(0.70-0.84)$

$0.17(0.15-0.20)$

$63(36-97)$

$0.31(0.25-0.37)$

$0.25(0.23-0.29)$

$0.13(0.10-0.17)$

$0.10(0.09-0.11)$

$72(41-110)$

$0.34(0.28-0.41)$

$0.27(0.24-0.30)$ data over this time. Although the time period considered is too short to be able to draw any firm conclusions, the median value gradually decreased year on year, from $0.25 \mu \mathrm{mol} / \mathrm{mol}$ in 2006 to $0.13 \mu \mathrm{mol} / \mathrm{mol}$ in 2010 . The proportion of samples exceeding the creatinine-corrected 95th percentile background level has also decreased, from $48 \%$ in 2006 to $10 \%$ in 2010 .

Modelling of the non-occupationally exposed data

The results of the two models on the non-occupationally exposed dataset are given in Table 3. In the fixed-creatinine model, time of day of sample had an effect, with values rising by $63 \%$ from 2 am to $2 \mathrm{pm}$. An effect was also determined for log-creatinine with coefficient 0.77 (95\% CI 0.70-0.84).

In the model with creatinine-corrected urinary thallium as the dependent variable, time of day was found to have a similar effect, with levels predicted to rise by $72 \%$ from 2 am to $2 \mathrm{pm}$. In this case, a gender difference was also found: Urinary thallium levels were predicted to be $0.13 \mu \mathrm{mol} / \mathrm{mol}$ creatinine for women and $0.10 \mu \mathrm{mol} / \mathrm{mol}$ creatinine for men.

Neither smoking nor age was found to have an effect in either model. Between- and within-person components of variation were similar to each other and modest in both models. The fixed-creatinine model estimated $\sigma_{\text {between-person }}$ at 0.31 and $\sigma_{\text {within-person }}$ at 0.25 , whilst for the creatininecorrected model their values were 0.34 and 0.27 , respectively.

Modelling of the whole dataset

Age, gender and smoking status were all found to have no statistically significant effect in the model. Likewise there were no significant differences between non-occupationally exposed people and general workers, but thallium workers had significantly higher values than the other two groups.

Results of the model are provided in Table 4. The logcreatinine coefficient was 0.58 (95\% CI $0.54-0.63)$. 
Multiplicative factors for predicted urinary thallium concentrations relative to those of non-occupationally exposed people were 1.27 (95\% CI 1.17-1.38) for general workers and 2.53 (95\% CI 1.96-3.24) for thallium workers.

In terms of variability, the results from the model fitted to the whole dataset broadly agreed with those of the previous models-non-occupationally exposed people exhibited modest between- and within- person variability components of 0.31 (95\% C.I. 0.26-0.38) and 0.28 (95\% C.I. 0.25-0.32), respectively. For general workers, they were similar (0.24 and 0.39 , respectively), but thallium workers displayed more variability $(1.02$ and 0.58 , respectively).

\section{Discussion}

The uncorrected 95th percentile background level of $0.40 \mu \mathrm{g} / \mathrm{l}$ compares well with other studies using ICP-MS to analyse samples from non-occupationally exposed adults. The US NHANES study (Centers for Disease Control and Prevention 2009, 2011) had 95th percentiles ranging from 0.40 to $0.45 \mu \mathrm{g} / \mathrm{l}$ in the five surveys between 1999 and 2007; Heitland and Köster (2006) found a level of $0.47 \mu \mathrm{g} / \mathrm{l}$; Hoet et al. (2013) found a level of $0.5 \mu \mathrm{g} / \mathrm{l}$. Creatinine-corrected 95th percentiles were also published by the US NHANES and Hoet studies. The US NHANES values ranged from 0.19 to $0.21 \mu \mathrm{mol} / \mathrm{mol}$ creatinine, and the Hoet value was $0.22 \mu \mathrm{mol} / \mathrm{mol}$ creatinine. These are slightly lower than the value found by this study of $0.27 \mu \mathrm{mol} / \mathrm{mol}$ creatinine across both genders.

The modest level of between-person variation (SD: $0.07 \mu \mathrm{mol} / \mathrm{mol}$ creatinine) in the non-occupationally

Table 4 Results for uncorrected urinary thallium concentrations from the Bayesian model over the whole log-transformed dataset

\begin{tabular}{lc}
\hline & $\begin{array}{l}\text { Estimate (95 \% confidence } \\
\text { interval) }\end{array}$ \\
\hline Intercept & $-1.29(-1.39$ to -1.18$)$ \\
Creatinine correction exponent & $0.58(0.54$ to 0.63$)$ \\
Fixed effect for general workers & $0.24(0.16$ to 0.32$)$ \\
Fixed effect for thallium workers & $0.93(0.68$ to 1.18$)$ \\
Multiplicative factor for general workers & $1.27(1.17$ to 1.38$)$ \\
Multiplicative factor for thallium & $2.53(1.96$ to 3.24$)$ \\
$\quad$ workers & $0.31(0.26$ to 0.38$)$ \\
$\sigma_{\text {between-unexposed }}$ & $0.24(0.18$ to 0.30$)$ \\
$\sigma_{\text {between-general-worker }}$ & $1.02(0.86$ to 1.22$)$ \\
$\sigma_{\text {between-thallium-worker }}$ & $0.28(0.25$ to 0.32$)$ \\
$\sigma_{\text {within-unexposed }}$ & $0.39(0.35$ to 0.42$)$ \\
$\sigma_{\text {within-general-worker }}$ & $0.58(0.53$ to 0.63$)$ \\
$\sigma_{\text {within-thallium-worker }}$ &
\end{tabular}

exposed data is indicative of a highly homogenous group. This is likely to be as a result of the method for recruitment of the volunteers. The majority of samples were collected from laboratory staff and their friends/family, and therefore, there was little geographical or socioeconomic variation within the group. Further work with a more diverse sample population would be required to investigate whether or not the levels of variation seen within this study are representative of the general population. However, the reasonably small amount of variation from the general workers (SD: $0.15 \mu \mathrm{mol} / \mathrm{mol}$ creatinine) indicates that population variability may be low. Although the workers in this subset have had no reason to specifically monitor thallium exposure, this does not mean that some instances of occupational exposure could not have taken place. This would explain the slightly higher variation than the nonoccupationally exposed group. The variation of the thallium worker subset is much higher (SD: $1.96 \mu \mathrm{mol} / \mathrm{mol}$ creatinine), reflecting the fact that although most of the samples have low thallium levels, there are also significant numbers of samples with higher levels (see Fig. 1).

Comparing the worker data to the calculated background level, $39 \%$ of thallium worker samples had a urinary thallium concentration exceeding the 95th percentile background level. Only $9 \%$ of general worker samples exceeded the background level. Combined with the knowledge that mixed effects models over the whole dataset showed that thallium workers had significantly higher thallium concentrations than general workers, these values suggest that in workplaces that use thallium, a measurable degree of occupational exposure is occurring in a substantial number of cases.

There is some uncertainty of the merit of creatinine correction - the German $\mathrm{RV}_{95}$ values (Umweltbundesamt 2012) are reported uncorrected; however, work such as the US NHANES study (Centers for Disease Control and Prevention 2009), the 2006 German study by Heitland and Köster and the 2013 Belgian study by Hoet et al. has reported both corrected and uncorrected data. The urinary thallium data collected for this study were all reported in both units of thallium concentration $(\mu \mathrm{g} / \mathrm{l})$ and also the creatinine-corrected units of $\mu \mathrm{mol} / \mathrm{mol}$ creatinine.

The data from the study of non-occupationally exposed people showed some minor problems with creatinine correction. Using uncorrected thallium levels and treating creatinine as a fixed effect, the Bayesian mixed effects models showed no significant differences in thallium concentrations between genders. However, using creatininecorrected thallium levels, the models predicted that males typically had $26 \%$ lower thallium levels than females. This is most likely an artefact caused by lower average creatinine values in females than males, due to their lower average muscle mass (Cocker et al. 2011; Arndt 2009). 
Fig. 2 Urinary thallium concentrations versus time of day of sample micturition, with predictions from the linear mixed effects model on the unexposed dataset.

a Uncorrected thallium concentrations $(\mathrm{nmol} / \mathrm{l})$ divided by their corresponding creatinine concentrations $(\mu \mathrm{mol} / \mathrm{l})$ raised to the power 0.77. b Creatinine-corrected values (uncorrected concentrations divided by creatinine concentrations, $\mu \mathrm{mol} / \mathrm{mol})$

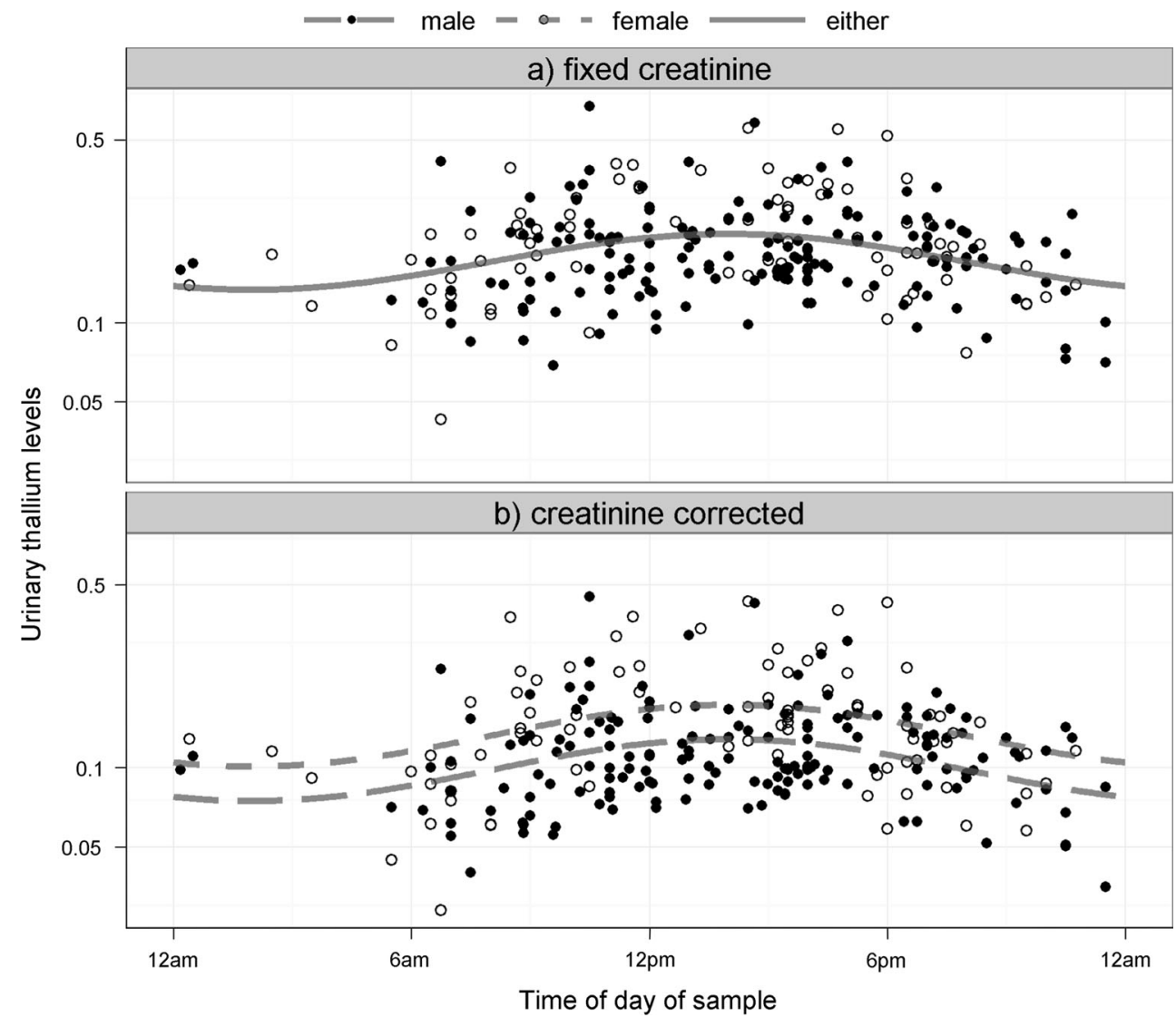

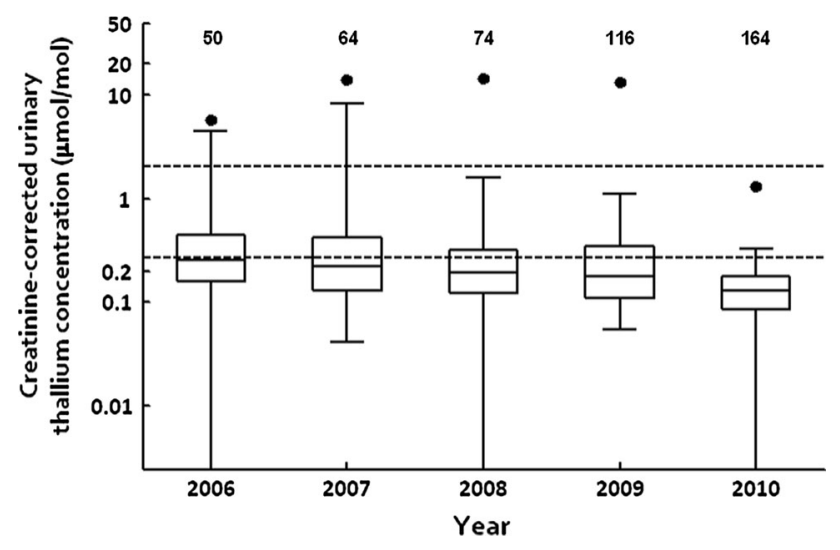

Fig. 3 Boxplots of creatinine-corrected urinary thallium levels in workers, split by the year of sample micturition. The boxes represent the 25th, 50th and 75th percentiles, whilst the bars extend to the 10th and 90th percentiles. The single point represents the highest recorded value in that particular year. The number of observations represented by each plot is displayed at the top

Such trends may also be observed in data from the US NHANES surveys (carried out from 1999 to 2007). Similarly to our study, the uncorrected 95th percentile values in the NHANES studies were comparable between genders (mean: $0.43 \mu \mathrm{g} / \mathrm{l}$ in males, $0.44 \mu \mathrm{g} / \mathrm{l}$ in females), and for the creatinine-corrected results, thallium levels in males were approximately $17 \%$ lower in males than in females (mean: $0.178 \mu \mathrm{mol} / \mathrm{mol}$ creatinine in males, $0.215 \mu \mathrm{mol} / \mathrm{mol}$ creatinine in females) (Centers for Disease Control and Prevention 2011). However, the model fitted to uncorrected data from non-occupationally exposed people suggests that the best fit to the data is achieved when the uncorrected values are divided by creatinine raised to the power 0.77 . (A slightly lower figure of 0.58 was estimated over all the data.). Since the exponent is closer to one than to zero and statistically significant, on balance this study suggests it is better to creatinine correct than not.

Other findings from the non-occupationally exposed data were consistent between the creatinine-corrected and fixed-creatinine models. There was no correlation betweenthallium concentration and smoking or age. However, an effect of the time of day (at which the sample was taken) on the thallium concentration was observed. A cyclic pattern was observed, with thallium levels higher during the day and lower at night. This trend was modelled using the assumption that the cyclic effect followed a sine curve and repeated over a 24-h cycle, as displayed in Fig. 2. In the creatinine-corrected model, thallium levels at 14:00 were found to be $63 \%$ (36-97\%) higher than those at 02:00. This effect was also present in the fixed-creatinine model, removing the possibility that it was an artificial effect of 
creatinine correction. This finding indicates significant diurnal variations in the excretion of thallium in the urine. To compensate for this effect, a 24-h total urine collection could be taken for analysis of thallium concentration; however, this is not practicable for biological monitoring in the workplace. Instead, it is recommended that future studies on thallium simply record the time of day of sample micturition. Further work could then be undertaken to investigate the effect of the time of day of sample micturition on the thallium concentration of occupational samples.

The possibility of a time trend in the thallium concentrations in all workers was also investigated. Although the 2006-2010 time period studied is too short for any definite conclusions to be drawn, the fact that the median value gradually decreased year on year, from $0.25 \mu \mathrm{mol} / \mathrm{mol}$ in 2006 to $0.13 \mu \mathrm{mol} / \mathrm{mol}$ in 2010 , and that the proportion of samples exceeding the creatinine-corrected 95 th percentile background level decreased from $48 \%$ in 2006 to $10 \%$ in 2010 (see Fig. 3), suggests a trend of decreasing occupational exposure over the period studied.

\section{Conclusions}

This study has established 95th percentile reference values for thallium in urine, $(0.27 \mu \mathrm{mol} / \mathrm{mol}$ creatinine creatininecorrected and $0.40 \mu \mathrm{g} / \mathrm{l}$ uncorrected) from a UK sample group not occupationally exposed to thallium. Thallium levels in people working with thallium were found overall to have significantly higher levels than volunteers and general workers. Over the entire time period 1995-2010, it was seen that $39 \%$ of thallium worker and $9 \%$ of general worker samples had a thallium concentration exceeding the 95th percentile background level. However, examination of the 2010 data showed that $90 \%$ of all workers had urinary thallium levels below the 95th percentile background level.

Acknowledgments This study was funded by the Health and Safety Laboratory Investment Research Programme. The authors would like to thank Dr Mary Trainor, Kate Jones, Dr John Cocker and Dr Emma Tan of HSL for their support.

Conflict of interest The authors declare that they have no conflict of interest.

\section{References}

ACGIH (2012) TLVs and BEIs. ACGIH Signature Publications, Cincinnati

Arndt T (2009) Urine-creatinine concentration as a marker of urine dilution: reflections using a cohort of 45,000 samples. Forensic Sci Int 186(1-3):48-51
Caldwell KL, Hartel J, Jarrett J, Jones RL (2005) Inductively coupled plasma mass spectrometry to measure multiple toxic elements in urine in NHANES 1999-2000. At Spectrosc 26(1):1-7

Canadian Council of Ministers of the Environment (1999) Canadian Soil Quality Guidelines for the Protection of Environmental and Human Health

Centers for Disease Control and Prevention (2009) NHANES fourth national exposure report [Online]. http://www.cdc.gov/exposure report/pdf/FourthReport.pdf. Accessed 10 March 2011

Centers for Disease Control and Prevention (2011) NHANES fourth national exposure report, updated tables, February 2011 [Online]. http://www.cdc.gov/exposurereport/pdf/Updated_ Tables.pdf. Accessed 10 March 2011

Cocker J, Mason HJ, Warren ND, Cotton RJ (2011) Creatinine adjustment of biological monitoring results. Occup Med (Lond) 61(5):349-353

Health and Safety Executive (1997) Biological monitoring in the workplace: a guide to its practical application to chemical exposure (HSG 167). HSE Books, Sudbury

Health and Safety Executive (2007) EH40/2005 workplace exposure limits [Online]. http://www.hse.gov.uk/coshh/table1.pdf. Accessed 15th July 2011

Heitland O, Köster HD (2006) Biomonitoring of 30 trace elements in urine of children and adults by ICP-MS. Clin Chim Acta 365:310-318

Helsel D (2010) Much ado about next to nothing: incorporating nondetects in science. Ann Occup Hyg 54(3):257-262

Hoet P, Jacquerye C, Deumer G, Lison D, Haufroid V (2013) Reference values and upper reference limits for 26 trace elements in the urine of adults living in Belgium. Clin Chem Lab Med. doi:10.1515/cclm-2012-0688

Institut für Arbeitsschutz der Deutschen Gesetzlichen Unfallversicherung (2012) GESTIS international limit values [Online]. http://limitvalue.ifa.dguv.de/. Accessed 03 Oct 2012

Kazantzis G (2007) Thallium. In: Nordberg GF et al (eds) Handbook on the toxicology of metals. Elsevier Science Publishers B.V, China

Lunn DJ, Thomas A, Best N, Spiegelhalter D (2000) WinBUGS-a Bayesian modelling framework: concepts, structure, and extensibility. Stat Comput 10:325-337

Marcus RL (1985) Investigation of a working population exposed to thallium. J Soc Occup Med 35:4-9

McNaught AD, Wilkinson A (1997) IUPAC compendium of chemical terminology, 2nd ed. (the "Gold Book"). Blackwell Scientific Publications, Oxford

Pelclová D, Urban P, Ridzoň P, Šenholdová Z, Lukáš E, Diblík P, Lacina L (2009) Two-year follow-up of two patients after severe thallium intoxication. Hum Exp Toxicol 28:263-272

R Development Core Team (2010) R: a language and environment for statistical computing. R Foundation for Statistical Computing, Vienna, Austria. ISBN 3-900051-07-0. http://www.R-project.org/

Sherlock JC, Smart GA (1986) Thallium in foods and the diet. Food Addit Contam 3(4):363-370

Tsai Y, Huang C, Kuo H, Wang H, Shen W, Shih T, Chu N (2006) Central nervous system effects in acute thallium poisoning. Neuro Toxicol 27:291-295

Umweltbundesamt (2011) (German Federal Environment Agency) Health and environmental hygiene reference and HBM values (Definitions and Tables) [Online]. http://www.umweltbundesa mt.de/gesundheit-e/monitor/definitionen.htm. Accessed $20 \mathrm{Feb}$ 2012

Umweltbundesamt (2012) (German Federal Environment Agency) Reference values $\left(\mathrm{RV}_{95}\right)$ [Online]. http://www.umweltdaten.de/ gesundheit-e/monitor/tab-ref-values-as-sb-metals.pdf. Accessed 5th Oct 2012 
White MA, Sabbioni E (1998) Trace element reference values in tissues from inhabitants of the European Union. X. A study of 13 elements in blood and urine of a United Kingdom population. Sci Total Environ 216:253-270
Zhao G, Ding M, Zhang B, Lv W, Yin H, Zhang L, Ying Z, Zhang Q (2008) Clinical manifestations and management of acute thallium poisoning. Eur Neurol 60:292-297 